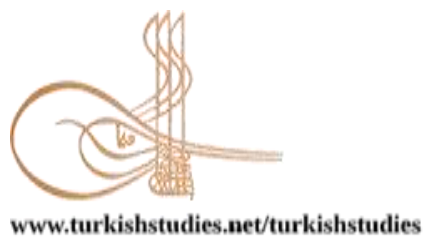

Turkish Studies

\title{
Covid 19 Pandemi Sürecinde Türkiye’de Uzaktan Eğitim Çalışmaları: Kastamonu Üniversitesi Örneği
}

\author{
Covid 19 Distance Education Studies in Turkey During The Pandemic Process: Case of \\ Kastamonu University
}

\author{
Elif Tarlakazan* - Burak Erhan Tarlakazan**
}

\begin{abstract}
Distance learning, also called e-learning and online learning, means the physical separation of teachers and students in education and communication through the use of various technologies. A growing number of universities in Turkey offer distance education opportunities. With the use of Internet technology in education, a comprehensive teaching service called "Distance Education" has emerged. The working group of the research consists of 88 students enrolled in the Graphic Design Department of the Faculty of Fine Arts and Design of Kastamonu University, who continue the spring 2019-2020 academic year with distance education during the pandemic process. The research was conducted to examine the Working Group's perspective on distance education and the problems and suggestions they faced. In this context, an ethical decision was made to be made by the Scientific Research and Publication Board of Kastamonu University, dated 12/10/2020 and numbered 1. The scale developed is limited by this research and the results obtained are specific to this group and cannot be generalized. The research was designed by qualitative research method. Qualitative research is a kind of social science research that is gathered with non-numerical data and aims to extract comments from data that help understand social life. In addition, calculations such as percentage frequency were used to interpret demographic features. At the end of the research, it was observed that students adopted distance education. In terms of continuity of Education; students who complete the process with distance education have expressed the disadvantages of distance education of design courses that should be carried out in workshops, studios, or classrooms. Besides, they have taken advantage of the advantages of distance education to work wherever and whenever they want. It is hoped that the study will guide distance education arrangements, contribute to the field writing, and shed light on those who will work on this issue.
\end{abstract}

Structured Abstract: Distance education is an education that is more flexible and adaptable to individual conditions than traditional education, where individuals are given the opportunity to learn on their own. It is aimed to eliminate the limitations in providing education services by distance education in part or whole and to provide educational opportunities to wider audiences.

\footnotetext{
* Dr. Öğr. Üyesi, Kastamonu Üniversitesi, Güzel Sanatlar ve Tasarım Fakültesi, Grafik Tasarımı Bölümü Asst. Prof. Dr., Kastamonu University, Fine Art and Design Faculty, Graphic Design Department ORCID 0000-0001-5381-9755

etarlakazan@kastamonu.edu.tr

** Doç. Dr., Kastamonu Üniversitesi, Güzel Sanatlar ve Tasarım Fakültesi, Grafik Tasarımı Bölümü Assoc. Prof. Dr., Kastamonu University, Fine Art and Design Faculty, Graphic Design Department ORCID 0000-0002-5826-2148

tarlakazan@hotmail.com

Cite as/ Atıf: Tarlakazan, E. \& Tarlakazan, B. E. (2020). Covid 19 pandemi sürecinde Türkiye'de uzaktan eğitim çalışmaları: Kastamonu Üniversitesi örneği. Turkish Studies, 15(7), ...-... https://dx.doi.org/10.7827/TurkishStudies.43704

Received/Geliş: 19 May/Mayıs 2020

Accepted/Kabul: 20 October/Ekim 2020

Copyright $($ ) MDE, Turkey

Checked by plagiarism software

Published/Yayın: 25 October/Ekim 2020

CC BY-NC 4.0
} 
In Özmen \& Gediz (2002: 25), Distance Education is defined as Education conducted using auxiliary mechanisms (such as letters, electronic devices) in situations where the environments of teaching staff and students are physically disjointed.

Although the expansion of the internet has blurred boundaries, distance learning technologies are divided into two forms of distribution: synchronous learning and asynchronous learning.

In concurrent (synchronous) learning, all participants are "ready" at the same time. In this context, it resembles traditional classroom teaching methods, although participants are remotely present. It requires a timeline to be edited. Examples of synchronous technology include Web conferencing, video conferencing, educational television, Instructional Television, Direct broadcast satellite (DBS), internet radio, live streaming, telephony, and web-based VoIP. Web conferencing software helps facilitate meetings in distance education courses, and often includes text chat, questionnaires, hand-lifting, emoticons, etc. includes additional interaction tools such as. These tools also allow students to listen to recordings of simultaneous sessions.

In Asynchronous Learning, participants have flexible access to course materials in their programs. Students are not required to be together at the same time.

In recent years, the advent of the internet and the widespread use of the computer have led to a major advance in remote training and studies. Distance education at the undergraduate level usually refers to students interested in learning materials at home or work. Educational support is provided through a virtual learning environment, telephone, email, or other electronic means.

The first distance education application in higher education in Turkey started with the open education programs of Eskişehir University. 5 and 12 of the Law No. 2547 of 6 November 1981 regulating Turkish Higher Education. (http://www.resmigazete.gov.tr/arsiv/17506.pdf), gave Turkish universities the right to make continuous and open education. On July 20, 1982, this training mission was given to Anadolu University, which completed its technological and scientific deficiencies in a very short time. Thus, Anadolu University Open Education Faculty has been tasked with the distance education service of open education services at the country level (Anadolu University, 2019). After Eskişehir Anadolu University, which is the pioneer of webbased distance education applications in Turkey, other universities have started to develop distance education applications (Arslan, 2019: 13).

\section{Purpose}

of The Department of Education of the Council of Higher Education to ensure that the education and training processes of higher education institutions are carried out as healthily as possible without interruption due to the outbreak of new Coronavirus disease (COVID-19).According to the article number of 75850160199-E.22344 and dated 19.03.2020, Kastamonu University decided to conduct the spring semester 2019-2020 by distance education with the idea of unity in practice during the pandemic process and continued the courses in digital media with the decision taken in the Graphic Design Department of the Faculty of Fine Arts and Design. The research was carried out to reveal the experiences experienced by the students of the department during this period.

Kastamonu University Distance Education Application and Research Center (KUZEM) established in 2013, undergraduate and graduate programs at the University of distance education application and Research Center; Principles of Atatürk and Revolution History I-II, Turkish I- II, Foreign Language I-II courses and coordination carries out the execution based on electronic communication technologies. However, in partnership with the Central Institute of Social Sciences and the Institute of natural and applied sciences, Distance Education carries out Master's degree programs without thesis. In the pandemic process, KUZEM is organized by opening up all faculty members and students to use the system with ease. uzem.kastamonu.edu.tr the user name from the address is the school number and the password is the TC number. In the same way, it has been made available to the faculty members by using the institution registration number and TC ID number, and manuals on how to use the system have been prepared quickly. According to April March 23 to April 20, 2020, 4,144 online courses have been created and 23,422 course contents have been uploaded by the instructors, according to Statistics data of Uzem. In addition, 22,966 students and 747 faculty members are enrolled in the distance education system.

The main objectives of the research are to describe the current situation and the effectiveness of the courses with the distance education system. 
To uncover these aims,

Students,

1. What is the level of knowledge for distance education?

2. How are Distance Education applications carried out?

3. Is it suitable for Distance Education Department courses? answers to such questions have been sought.

\section{Method}

The research is designed using qualitative research method. Qualitative research is an interrogator, interpreter and a method that tries to understand the form of the problem in its natural environment (Guba \& Lincoln, 1994: 163-194; Klenke, 2016). Descriptive research aimed to determine whether design lessons can be done with distance education during the pandemic process of students. In addition, in the research, it was tried to determine whether there are differences in situations such as gender differences and whether they have technical equipment or not. Quantitative data were analyzed using statistics such as frequency and percentage, while qualitative data were analyzed using the content analysis method. Content analysis will enable the collected data to be analyzed in depth rather than superficial and to reveal previously unclear themes and dimensions.

\section{Findings}

Barriers to effective distance education include barriers such as local distractions and unreliable technology, as well as students ' program costs, adequate contact with teachers and support services, and the need for more experience. In the definition of distance education, almost all participants gave similar responses and stated that courses were processed in a virtual environment.

Distance education was not considered sufficient by the department students who had tried and applied for courses with experience during this period when a traditional applied academic learning environment was not the same. In addition, distance learning programs can be difficult to organize and plan, especially because many of them are new programs and their organizational needs are different from a traditional learning program.

\section{Results}

This section provides the results based on the findings from the research and the recommendations related to these results.

The research was conducted during the COVID-19 pandemic in order to get the opinions of the students of the Graphic Design Department of the Faculty of Fine Arts and design of Kastamonu University about the functioning of the process.

The definition of Distance Education has been made according to its sub-purpose. Distance education is the education of students who are not always physically present in a school. Distance education is a way of distance learning without regularly communicating face-to-face with a teacher in the classroom. Distance education is by definition carried out through institutions. Geographical separation is inherent in distance learning, accessibility and convenience are important advantages of this style of Education. Distance learning sometimes connects like-minded students with social media user activities that students profile and share, and can reduce thoughts of isolation. They were seen to have information about what the distance education system means and its content in general.

Research 2. and 3. for their sub-purposes, they stated that distance education applications are treated like formal education in a virtual classroom environment in theoretical courses, but that the courses that should be done in a workshop environment in practical Department courses are not very efficient.

The most important result extracted from the research data is the transactional distance of distance education resulting from the lack of appropriate communication between the learner and the teacher. This difference has been observed if there is no communication between student and teacher and has direct effects on the learning process and future efforts in distance education. 
Communication in distance education between students and teachers and students and classmates is increasing with the many tools and programs offered by technological developments. Distance education in communication, especially communication between students and classmates, is an improvement made to provide distance education students with as many opportunities as possible in face-to-face education. Progress in distance education is increasing with continuous technological developments.

Distance education also provides individuals with a unique opportunity to benefit from the expertise and resources of the best universities currently available. Students can collaborate, share, ask questions, infer, and propose new methods and techniques for the continuous improvement of content. Distance education at your own pace on a mobile device such as a smartphone provides maximum flexibility and capability.

Distance education providers should begin to implement various strategies, techniques, and procedures to increase the amount of interaction between student and teacher. The use of information and communication technologies, including more frequent face-to-face training, teleconferencing, and the internet, should be ensured; the distance education system designed for educational continuity during the pandemic should not be generalized for each faculty and department; the distance education system used in the processing of theoretical courses should be revised and regulated for practical courses.

Remote training capabilities can also be planned separately and simultaneously to support face-toface training in applied areas. The availability and increased use of internet-based teleconferencing applications (including internet speed and quality) and Information-Communication Technologies in any environment must be ensured. Education and training plans should be made for similar situations like the COVID-19 pandemic process that we are currently experiencing. In this sense, possible scenarios should be produced and approaches to disrupting education in terms of early warning and precautions should be updated, lesson activities and schedules should be prepared and planning should be developed. The distance education system designed for educational continuity should be prepared for each faculty and department with its internal dynamics in mind. The distance education system, which seems more suitable for the processing of theoretical courses, can be evaluated separately with participatory and stakeholder views in terms of practical courses.

Keywords: Graphic design, distance education, pandemic, e-learning, students

Öz: Uzaktan eğitim; e-öğrenme ve çevrimiçi öğrenme olarak da adlandırılan, eğitimde öğretmen ve öğrencilerin fiziken ayrılması ve çeşitli teknolojilerin kullanımı ile iletişim kurulması anlamına gelmektedir. Türkiye'de giderek artan sayıda üniversite uzaktan eğitim imkânı sunmaktadır. İnternet teknolojisinin eğitimde kullanılmasıyla birlikte "uzaktan eğitim” adı verilen kapsamlı bir öğretim hizmeti ortaya çıkmıştır. Araştırmanın çalışma grubunu pandemi sürecinde 2019-2020 Bahar eğitim-öğretim dönemini uzaktan eğitimle devam ettiren Kastamonu Üniversitesi Güzel Sanatlar ve Tasarım Fakültesi Grafik Tasarımı Bölümünde kayıtlı 88 öğrenci oluşturmaktadır. Araştırma; çalışma grubunun uzaktan eğitime bakış açısını, karşılaştıkları problem ve önerilerini irdelemek amacıyla yapılmıştır. Bu kapsamda Kastamonu Üniveritesi Bilimsel Araştırma ve Yayın Etiği Kurulunun 12/10/2020 tarih ve 1 nolu kararınca araştırma yapılması için etik kurul kararı alınmıştır. Geliştirilen ölçek bu araştırmayla sınırlıdır ve elde edilen sonuçlar bu gruba özgüdür ve genelleme yapılamaz. Araştırma nitel araştırma yöntemiyle desenlenmiştir. Nitel araştırma, sayısal olmayan verilerle toplanan, sosyal yaşamı anlamaya yardımcı olan verilerden yorumlar çıkarmayı amaçlayan bir tür sosyal bilim araştırmasıdır. Ayrıca demografik özellikleri yorumlamak için yüzde frekans gibi hesaplamalar kullanılmıştır. Araştırma sonunda, öğrencilerin uzaktan eğitimi benimsedikleri görülmüştür. Eğitimin sürekliliği esasına göre; süreci uzaktan eğitimle tamamlayan öğrenciler; atölye, stüdyo veya derslikte yapılması gereken tasarım derslerinin uzaktan eğitimle yapılmasının dezavantajlarını dile getirmişlerdir. Bunun yanında uzaktan eğitimin; istedikleri yerde ve zamanda çalışabilme avantajlarından yararlanmışlardır. Çalışmanın uzaktan eğitim düzenlemelerine rehberlik etmesi, alan yazına katkıda bulunması ve bu konuda çalışma yapacaklara ışık tutması umulmaktadır.

Anahtar Kelimeler: Grafik tasarım, uzaktan eğtim, pandemi, e-öğrenme, öğrenci 


\section{Giriş}

Uzaktan eğitim yalın anlamıyla öğreten ve öğrenenin fiziksel olarak bir arada bulunmadığı bir eğitim biçimidir. En kısa ve en fazla kullanılan ifadelerden biri olarak; "zaman ve mekândan bağımsız eğitim şekli" olarak tanımlanabilir. Literatürde uzaktan eğitimle ilgili birçok tanım mevcuttur. "Uzaktan eğitim" terimi ilk olarak 1892 yılında Wisconsin Üniversitesi'nin kataloğunda geçmiştir (Kaya, 2002: 30).

Uzaktan eğitim, bireylere kendi kendilerine öğrenme imkânının sağlandığı, geleneksel eğitime göre daha esnek ve birey koşullarına uyarlanabilir bir eğitimdir. Uzaktan eğitimle eğitim hizmeti götürmekteki sınırlılıkların kısmen ya da tümüyle ortadan kaldırılarak eğitim imkânlarının daha geniş kitlelere ulaştırılması amaçlanmaktadır.

Özmen \& Gediz'de (2002: 25) Uzaktan eğitimi, öğretim elemanı ve öğrencilerin bulunduğu ortamların fiziksel olarak ayrık olduğu durumlarda, yardımcı mekanizmalar kullanılarak (mektup, elektronik cihazlar gibi) yapılan eğitim olarak tanımlamaktadır.

Ayrıca; tam zamanlı çalışanlar, askeri personel ve yerleşik olmayanlar ya da uzak bölgelerdeki sınıf derslerine katılamayan bireyler gibi geleneksel eğitim imkânı olmayan öğrencilere odaklanmıştır. Bununla birlikte, uzaktan eğitim, sürekli büyümeye işaret eden eğilimlerle eğitim dünyasının yerleşik bir parçası haline gelmiştir.

Son yıllarda internetin ortaya çıkışı ve bilgisayarın yaygın kullanımı, uzaktan verilen eğitim ve çalışmalarda büyük bir ilerlemeye yol açmıştır. Lisans düzeyinde uzaktan eğitim genellikle evde veya iş yerinde öğrenme materyalleri ile ilgilenen öğrenciler anlamına gelir. Eğitim desteği, sanal bir öğrenme ortamı, telefon, e-posta veya diğer elektronik yöntemlerle sağlanır.

Uzaktan eğitimin ana avantajı, öğrenmenizi iş ve ev yaşamınıza uygun hale getirmenize izin vermesidir. Genellikle kendi çalışma hızınızı da belirleyebilirsiniz. Ne zaman ve nerede çalışacağına öğrenci karar verir. Bağlantı kurmak için internete sahip olmak yeterlidir. Tam zamanlı bir derste olduğu gibi, öğrenciler planlama ve araştırma gibi faydalı, aktarılabilir beceriler kazandıklarını görebilirler. Uzaktan eğitim genellikle tam zamanlı dersten daha az maliyetlidir. Dezavantajı, bir kampüste olmanın ve günlük olarak diğer öğrencilerle omuzları ovuşturmanın rahatlığından zevk almamanızdır. Küresel eğitim, öğrencilere uzaktan eğitim ile dünyanın değișik ülkelerde bulunan üniversitelerin eğitim imkânlarından yararlanma imkânı sunmakta hatta bu üniversitelerden yüksek lisans veya doktora derecesi alabilme firsatı vermektedir (İşman, 2011: 4).

İnternet'in genişlemesi sınırları bulanıklaştırsa da, uzaktan eğitim teknolojileri iki dağıtım biçimine ayrılmıştır: Senkron öğrenme ve asenkron öğrenme.

Eşzamanlı (senkron) öğrenmede, tüm katılımcılar aynı zamanda "hazırdır". Bu bağlamda öğrenme, katılımcıların uzaktan bulunmasına rağmen geleneksel sınıf öğretim yöntemlerine benzemektedir. Düzenlenmesi için bir zaman çizelgesi gerektirir. Web konferans1, video konferans, eğitim televizyonu, öğretim televizyonu, doğrudan yayın uydusu (DBS), internet radyosu, canlı akış, telefon ve web tabanlı VoIP ... v.b. gibi senkron teknolojiye örnektir. Web konferans yazılımı uzaktan eğitim kurslarındaki toplantıları kolaylaştırmaya yardımcı olur ve genellikle metin sohbeti, anketler, el kaldırma, ifadeler vb. gibi ek etkileşim araçları içerir. Bu araçlar aynı zamanda öğrencilerin eşzamanlı oturumların kayıtlarını dinleyebilmelerini sağlar.

Eşzamanlı olmayan (asenkron) öğrenmede katılımcılar ders materyallerine kendi programlarında esnek bir şekilde erişir. Öğrencilerin aynı anda birlikte olmaları gerekmez. Uzaktan eğitimin en eski formu olan posta yazışmaları, mesaj panosu forumları, e-posta, video ve ses kayıtları, basılı materyaller, sesli posta ve faks gibi eşzamansız bir dağıtım teknolojisidir. Senkron ve asenkron öğrenme yöntemleri birleştirilebilir. 
Uzaktan eğitim esnek planlama yapısı ile kişisel sorumluluk ve taahhütlerin getirdiği birçok zaman kısıtlamasının etkilerini azalttığı için hem genel nüfus hem de işletmeler için eğitim ve öğretime erişimi genişletebilir.

Günümüz çevrimiçi iletişimi, öğrencilerin dünya çapında yüz yüze öğrenme için erişilemeyen akredite okullar ve programlarla bağlantı kurmasını sağlar. Uzaktan eğitim yoluyla küresel kurumlara katılma firsatı sağlanmış ve kurulan iletişim yoluyla öğrencilere çeşitli düşünceler sunulmaktadır. Bu yararlıdır, çünkü öğrenciler "yeni fikirleri kendileriyle birleştirme ve öğrenme için sağlam bir temel geliştirme" olanağına sahiptir. Eğitimde, öğrencilerin ders sırasında birbirleriyle etkili bağ kurma olasılı̆̆ını artırmak için, eğitmenler, ortak konumun ilişki kurma üzerindeki etkisinin üstesinden gelmek için farklı konumlardaki öğrenciler için benzer ödevler kullanmalıdır.

Uzaktan eğitimin en önemli özelliği; öğretmen ve öğrencilerin coğrafi olarak farklı yerlerde bulunmaları, yer ve zamandan bağımsızlık, öğretmen, öğrenci ve ders içeriklerinin uzaktan eğitimin kendine özgü öğrenme ortamlarında bir araya gelmesi ve öğrencilerin kendi kendilerine öğrenmeleri olarak suralanabilir (Yavuz, 2016: 6). Örneğin, öğrenciler ihtiyaca göre birden fazla kez derslerini gözden geçirebilir. Öğrenciler daha sonra zaten sahip oldukları veya kolayca kavrayabilecekleri kavramlar üretirken daha zayıf konularına daha fazla odaklanarak dersleri öğrenmelerine uyacak şekilde manipüle edebilirler.

Türkiye'de yükseköğretimde ilk uzaktan eğitim uygulamas1, Eskişehir Üniversitesi açıköğretim programları ile başlamıştır. Türk yükseköğretimini düzenleyen 6 Kasım 1981 tarih ve 2547 sayll Kanun'un 5 ve 12. maddeleri (http://www.resmigazete.gov.tr/arsiv/17506.pdf), Türk üniversitelerine sürekli ve açıköğretim yapmak hakkını tanımıştır. 20 Temmuz 1982'de bu eğitim, teknolojik ve bilimsel eksikliklerini çok kısa sürede tamamlayan Anadolu Üniversitesine verilmiştir. Böylece Anadolu Üniversitesi Açıköğretim Fakültesi ülke düzeyinde açıköğretim hizmeti uzaktan öğretim hizmeti ile görevlendirilmiştir (Anadolu Üniversitesi, 2019). Türkiye'de web tabanlı uzaktan eğitim uygulamalarının öncüsü olan Eskişehir Anadolu Üniversitesinden sonra diğer üniversiteler de uzaktan eğitim uygulamalarını geliştirme çalışmalarına başlamıştır (Arslan, 2019: 13).

Devlet okullarında belirli bölümler için uygulanan online eğitim sistemi giderek yaygınlaşan ve gelişen bir eğitim modelidir. Bir anlamda Corona Virüs tedbirleri kapsamında çok daha yaygın bir kullanım alanına sahip olan bu sistem, klasik eğitim sunan ortaöğretim ve üniversitelerin tedbir amaçlı olarak öğrencilerin fiziki bir ortamda ders görmelerinin sakıncalı olabileceği gerekçesi, online eğitimin daha da yaygınlaşmasını sağlamıştır (Genç ve Gümrükçüoğlu, 2020:406).

Uzaktan eğitimde kullanılan eğitim yönetim sistemleri uzaktan eğitim faaliyetlerini kolaylaştırmak ve daha sistematik, planlı bir şekilde gerçekleştirmek amacıyla kullanılmaktadır. Bu öğrenme yönetim sistemleri aracıllğıyla eğitim faaliyetleri gerçekleştirilmekte, değerlendirilmekte ve izlenebilmektedir. Bu nedenle öğrenme yönetim sistemleri sürekli olarak geliştirilebilen sistemlerdir (Duran ve diğ., 2006: 1).

\section{Araştırmanın Amacı ve Önemi}

Çin de başladığı varsayılan koronavirüs (Covid-19) pandemisi kısa zamanda Çin sınırlarını aşarak tüm dünyayı etkisi altına almış ve başlangıç yeri olan Çin den daha fazla yıkıma neden olmuştur (Kaynak, 2020:636). Yeni Koronavirüs Hastalığ (COVID-19) salgını dolayısıyla yükseköğretim kurumlarının eğitim ve öğretim süreçlerinin mümkün olduğunca kesintiye uğramadan sağlıklı şekilde yürütülebilmesi için Yükseköğretim Kurulu Eğitim-Öğretim Dairesi Başkanlığının 75850160-199-E.22344 sayı ve 19.03.2020 tarihli yazısına istinaden Kastamonu Üniversitesi pandemi sürecinde uygulamada birlik düşüncesiyle, 2019-2020 Bahar Dönemini 
uzaktan eğitim ile yapma kararı almış ve Güzel Sanatlar ve Tasarım Fakültesi Grafik Tasarım Bölümü'de alınan kararla derslere dijital ortamda, uzaktan eğitimle devam etmiştir. Araştırma bu süreçte bölüm öğrencilerinin yaşadığı tecrübeleri ortaya çıkarmak amacıyla yapılmıştır.

Kastamonu Üniversitesi Uzaktan Eğitim Uygulama ve Araştırma Merkezi (KUZEM) 2013 yılında kurulan Uzaktan Eğitim Uygulama ve Araştırma Merkezi üniversitemiz Önlisans ve Lisans Programlarında; Atatürk İlkeleri ve İnkılap Tarihi I-II, Türk Dili II ve Yabancı Dil I-II derslerini elektronik iletişim teknolojilerine dayalı olarak yürütülmesini ve koordinasyonunu gerçekleştirmektedir. Bununla birlikte merkez Sosyal Bilimler Enstitüsü ve Fen Bilimleri Enstitüsü ile ortaklaşa Uzaktan Eğitim Tezsiz Yüksek Lisans Programlarını yürütmektedir. Pandemi sürecinde tüm öğretim üyeleri ve öğrencilerinin kullanımına açılarak düzenlenen KUZEM, öğrencilerin kolaylıkla sistemi kullanması için uzem.kastamonu.edu.tr adresinden kullanıcı adı okul numarası ve şifre ise TC numarası ile erişim izni vermiş̧tir. Aynı şekilde öğretim üyeleri içinde kurum sicil no ve TC kimlik no kullanarak erişime açılmış ve hızlı bir şekilde sistemden nasıl faydalanılacağına yönelik klavuzlar hazırlanmıştır. UZEM'in istatistik verilerine göre; 23 Mart-20 Nisan 2020 tarihleri arasındaki 4,144 online ders oluşturulmuş, öğretim elemanları tarafından 23,422 ders içeriği yüklenmiştir. Ayrıca 22,966 öğrenci ve 747 öğretim elemanı uzaktan eğitim sistemine kayıt edilmiştir.

Uzaktan eğitim sistemiyle yapılan derslerin etkililiği, mevcut durumu betimlemek araştırmanın ana amaçlarıdır.

$\mathrm{Bu}$ amaçları ortaya çıkarmak için,

Öğrencilerin,

1. Uzaktan eğitime yönelik bilgi düzeyleri nedir?

2. Uzaktan eğitim uygulamaları nasıl yapılmaktadır?

3. Uzaktan eğitim bölüm derslerinin yapılabilmesi için uygun mudur? Gibi sorulara cevap aranmıştır.

\section{Yöntem}

Araştırma, nitel araştırma yöntemi kullanılarak desenlenmiştir. Nitel araştırma, incelediği probleme ilişkin sorgulayıcı, yorumlayıcı ve problemin doğal ortamındaki biçimini anlama uğraşı içinde olan bir yöntemdir (Guba \& Lincoln, 1994: 163-194; Klenke, 2016). Anketin uygulanabilmesi için T.C. Kastamonu Üniversitesi Bilimsel Araştırma ve Yayın Etiği Kurulunun/10/2020 Tarih ve nolu karar sayısı ile etik kurul izni alınmıştır. Verilerin elde edilmesi için google form aracılığıyla oluşturulmuş olan anket katılımcıların mail adreslerine gönderilmiştir. Betimsel nitelik taşıyan araştırma, öğrencilerin pandemi sürecinde uzaktan eğitim ile tasarım derslerinin yapılıp yapılamayacağını saptamayı amaçlamıştır. Ayrıca araştırmada cinsiyet farklılığının ve teknik ekipmana sahip olup olmama gibi durumlarda farklılık olup olmadığı belirlenmeye çalışılmıştır. Nicel veriler frekans ve yüzde gibi istatistikler kullanılarak analiz edilmiş, nitel veriler ise içerik analizi yöntemi ile çözümlenmiştir. İçerik analizi, toplanan verilerin yüzeysel değil derinlemesine analiz edilmesini ve önceden belirgin olmayan temaların ve boyutların ortaya çıkmasını sağlayacaktır.

\section{Çalışma Grubu}

Çalışma grubunu, Kastamonu Üniversitesi Güzel Sanatlar ve Tasarım Fakültesi Grafik Tasarım Bölümünde öğrenim gören ve çalışmanın amacı, kapsamı ve süreci hakkında bilgilendirilen çalışmaya gönüllü olarak katılmak isteyen 88 öğrenci oluşturmaktadır. Araştırma kapsamında öğrencilerin demografik özellikleri Tablo.1 de gösterilmiştir. 


\begin{tabular}{lccc}
\multicolumn{4}{c}{ Tablo 1: Çalışma grubunun cinsiyete göre dağılımı } \\
\hline \multirow{3}{*}{ Cinsiyet } & Değişken & $\mathrm{f}$ & $\%$ \\
& Kadın & 69 & 78,4 \\
& Erkek & 19 & 21,6 \\
\hline TOPLAM & & 88 & 100 \\
\hline
\end{tabular}

Tablo 1 incelendiğinde çalışma grubunun; \%78,4’ünün (69) kadın öğrencileri, \% 21,6'sının (19) erkek öğrencileri oluşturduğu görülmektedir.

Tablo 2: Çalışma grubunun sinıflara göre dağılımı

\begin{tabular}{cccc}
\hline & Değişken & $\mathrm{f}$ & $\%$ \\
Öğrenim & 1. sinıf & 8 & 9,1 \\
Düzeyi & 2.sinıf & 24 & 27,3 \\
& 3.sinıf & 27 & 30,7 \\
& 4. sinıf & 29 & 33 \\
\hline TOPLAM & & 88 & 100 \\
\hline
\end{tabular}

Tablo 2 incelendiğinde çalışma grubunun; \%9,1'inin (8) 1. sınıf öğrencileri, \% 27,3'ünün (24) 2. sinıf öğrencileri, \%30,7'sinin (27) 13. sinıf öğrencileri, \%33'ünün (29) 4. sinıf öğrencileri oluşturduğu görülmektedir.

Tablo 3: Çalışma grubunun yaş aralığına göre dağılımı

\begin{tabular}{cccc}
\hline \multirow{3}{*}{ Yaş } & Değişken & $\mathrm{f}$ & $\%$ \\
& $18-24$ yaş & 85 & 96,6 \\
& $25-35$ yaş & 2 & 2,3 \\
TOPLAM & $36-40$ yaş & 1 & 1,1 \\
\hline
\end{tabular}

Tablo 3 incelendiğinde çalışma grubunun; \%96,6'sının (85) 18-24 yaş, \% 2,3'ünün (2) 2535 yaş, \%1,1'inin (1) 36-40 yaş aralığında olduğu görülmüştür. 36-40 yaş aralığında olan 1 öğrencinin 2. üniversitesini okumakta olduğu tespit edilmiştir.

\section{Veri Toplama}

Uzaktan eğitimin etkililiğini belirlemek için araştırmacılar tarafından oluşturulan veri toplama seti 2 bölümden oluşmaktadır. 1. Bölüm; cinsiyet, yaş ve öğrenim düzeyi gibi demografik soruları ve teknoloji kullanımı ile ilgili; uzaktan eğitim donanımlarının olup olmadığı, günlük internet kullanımı, bildiğiniz uzaktan eğitim sistemleri... v.b. gibi çoktan seçmeli soruları içermektedir. 2. Bölüm; uzaktan eğitim sisteminin tanımı, faydaları, öğretmen ve öğrencinin rolü, derslerin izlenmesi, sürenin yeterliliği, ödev yükleme-gönderme aşamasında karşılaşılan sorunlar ve bölüm derslerinin uzaktan eğitimle işlenmesinin mümkünlüğü gibi açık-uçlu soruları kapsamaktadır. Ölçeğin uygulanması sırasında boş bırakılmaması gerekliliği belirtilmiş ve boş olduğu tespit edilen veriler analize dâhil edilmemiştir.

\section{Verilerin Analizi}

Araştırma amacına ulaşmak için öğrencilere uygulanan ölçekte çalışma grubunun kişisel özellikleri (cinsiyet, yaş, sınıf, bilgisayar sahibi olup olmama, günlük sosyal medya kullanımı) gibi tanımlama analizlerinde Frekans (f) alma tekniği uygulanmıştır.

İçerik analizinde ise derinlemesine bilgilerin elde edilmesi için gerçekleştirilmesi gereken tematik kodlama yapılırken, tutarlılığ 1 sağlamak amaçtır. Veri analizinde öğrencilerin kişisel bilgileri korumak esasıyla kodlarla örneğin (Ö. 21) gibi ifade edilmiştir. Temaların altında yer alan verilerin anlamlı bir bütün oluşturup oluşturmadığına dikkat edilmesi gerekmektedir (Yıldırım ve Şimşek, 2008: 237). Araştırma sorularının cevaplanmasında sırasıyla şu işlemler uygulanmıştır: 
- Öğrencilerin verdikleri yanıtların dikkatli bir şekilde okunması.

- Öğrencilerin verdiği dikkat çeken yanıtların tespiti.

- İfadelerin yer aldığı kelime gruplarının işaretlenmesi ve serbest kod (free cases) listesinin oluşturulması.

- Serbest kod listesindeki kodların yeniden incelenerek benzer içeriğe sahip kodları ebeveyn ve çocuk kategorilerinin oluşturulması ve oluşturulan kategorilere atamaların gerçekleştirilmesi.

- Kod ve kategori bağlantısının kurulması ve bir model oluşturulması.

- Modelin oluşturulma biçimi doğrultusunda okunması ve yorumların yapılması (Tarlakazan, 2010: $5)$.

\section{Bulgular ve Yorum}

Araştırmada ele alınan; Uzaktan eğitim nedir ve avantaj ve dezavantajları nelerdir? Şeklinde ifade edilen sorunun yanıtına ilişkin bulgular bu başlık altında yorumlanmıştır.

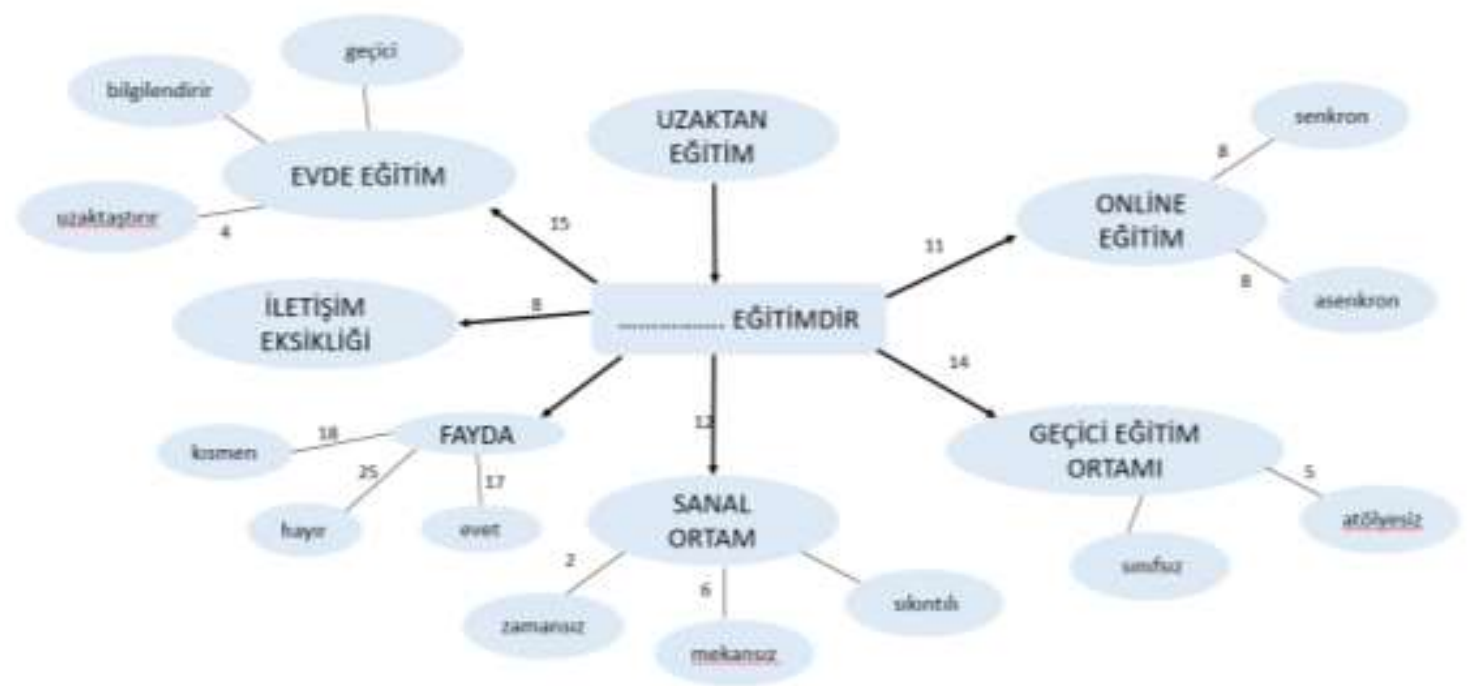

Şekil 1. Uzaktan eğitim kavramı ve faydasına yönelik şematik gösterim

Öğrenciler tarafından verilen ifadeler şema üzerinde gösterilmeye çalışılmıştır. Şemanın anlaşı1ır olması için bazı açıklamalar yapmakta fayda görülmektedir. Uzaktan eğitimin tanımlaması ve faydasına yönelik ifadelerin yer aldığı şemada toplam 153 kodun, 21 kategoride atamaları yapılmış olup; tek yönlü oklar birincil, diğerleri ise ikincil bağlantıları ifade etmektedir. Bağlantılar üzerindeki sayısal değerler deneklerin uzaktan eğitimle yapılan öğrenmeden ne anladıklarına dair yüklemeleri ifade etmektedir. Sayısal değeri bulunmayan yüklemeler rakamsal olarak "1" değerini taşımaktadır. Bir denek bir veya daha fazla yükleme yapabileceği için uygulamaya katılan denek sayısı ile yükleme yapan denek sayısı birbirinden farklı olabilir. Model incelenirken bu durum göz önünde bulundurulmalıdır.

Şekil 1 incelendiğinde uzaktan eğitim yapılan öğrenmenin tanımı sorusuna derinlemesine cevap arandığı görülmektedir. Öğrencilerden tüm süreci ve uygulamayı değerlendirecek şekilde yanıtlar beklendiği belirtilmiştir. Bu uyarılar ışı̆̆ında online, evde yapılacak geçici bir eğitim ortamı olduğu ve iletişim eksikliği konusunda yüklemeler yapıldığı görülmüştür.

Ö.12“...sanal ortamda, canll, görüntülü, sesli ve interaktif olarak

derslerin işlendiği, uzaktan fakat yüz-yüze üniversite eğitiminin 
verildiği bir ĕgitim sistemidir"

Ö.54 “...zamandan ve mekândan tamamen bağımsız bir şekilde öğrencilerin gelme zorunluluğu olmaksızın mevcut var olan bilgisayar teknolojileri vasitası ile tamamen sanal ortamda canlı, görüntülü, sesli olarak derslerin işlendiği, katılımcının istediği zaman bunları tekrar izleyebileceği ders ortamıdır” Ö.15 “...Uzaktan öğretim, öğrencinin ve öğretim üyesinin kampüse gelme zorunluluğunun bulunmadiğg, tamamen sanal ortamda, canl, görüntülü, sesli ve interaktif olarak derslerin işlendiği sistemdir" Ö.23 “...kampüse gelme zorunluluğu olmaksızın mevcut var olan bilgisayar teknolojileri vasitasi ile tamamen sanal ortamda canl,, görüntülü, sesli olarak derslerin işlendiği, katılımcının istediği zaman bunları tekrar izleyebileceği ĕgitimdir"

Ö.36“...Sosyal mecralar ve uygulamalar aracılığ dersleri aldı ̆̆ımı sistemdir"

Ö.88 “...Internet üzerinden genellikle teorik dersleri aldı ̆̆ımız sistemdir"

Ö.2 “...Uzaktan derslerimizin devamlılı̆̆ını să̆lamak ve ĕgitimimizin aksamasinı önlemek”

Etkili uzaktan eğitimin önündeki engeller arasında, yerel dikkat dağıtıcı unsurlar ve güvenilmez teknoloji gibi engeller ile öğrencilerin program maliyetleri, öğretmenler ve destek hizmetleriyle yeterli temas ve daha fazla deneyime ihtiyaç vardır. Uzaktan eğtim tanımlamasında hemen hemen tüm katılımcılar benzer yanıtlar vermişler ve sanal ortamda derslerin işlendiğini belirtmişlerdir. Diğer bir anlam yüklemesi ise avantaj ve dezavantaj konusunda yapılmıştır.

Ö.13“...Faydalı bir sistem olduğunu düşünüyorum ama uygulama dersleri açısından biraz zorlayıcı olabiliyor. Çünkü örgün eğitimde hocamızın verdiği ödevi hemen yapıp gösterebiliyorduk şimdi mail atıyoruz hocamız bize tekrar dönüyor birza zaman kaybı oluyor " Ö.4 “...kriz zamanlarl için ideal ancak yüz yüze eğitimin yerini tutmaz örneğin bu sistem sağllk raporlu öğrencilerin eğitiminin sekteye uğramaması için yürürlüğe konabilir. Böylece devasızlıktan kalmak söz konusu olmaz”

Ö.18“...Uygulamalı dersleri işlerken, görmek dokunmak ve yapılan işleri hissederek yapmak çok daha farklı bir durumdur. Ancak uzaktan eğitim derslerinde ise bağlantı kopmaları olabiliyor. Bu nedenle çok gerekmedikçe faydalı bulmuyorum" Ö.46“...Ödev odakl bir sistem gibi geliyor tabi şu anda yaşanan 
salgından dolayı eve hapsolmanın verdiği psikoloji yüzünden de

biraz zorlayıcı yanları oluyor onun harici gayet esnek"

Ö.52“...Asla. Yaptı̆̆ım ödevlerden asla verim alamadım.

Öğretmenlerimizle derslerde her şekilde soru imkânımız vardı,

atölye ortamı bize daha çok verim sağllyordu, eğitimimiz daha

iyi ilerliyordu daha çok ama çok faydalıydı. Uzaktan eğitimde

ise böyle imkanlarımı yok maalesef"

Uzaktan eğitimle, geleneksel bir uygulamalı akademik öğrenme ortamının aynı olmadığı bu dönemde tecrübe ile denenmiş ve uygulamalı dersleri olan bölüm öğrencileri tarafından yeterli görülmemiştir. Ayrıca, uzaktan eğitim programı organize etmesi ve planlaması zor olabilir, özellikle birçoğu yeni programlar olduğu ve organizasyonel ihtiyaçları geleneksel bir öğrenme programından farklı olduğu için zorluk yaşanabilmektedir. Bölüm bazında baktığımızda tüm derslere genellenemeyeceği bulgusuna ulaşılmıştır.

Ölçek sorularından öğretmen ve öğrenci rollerine yönelik sorunun bulgularına ulaşmak için aynı işlemler uygulanmıştır.

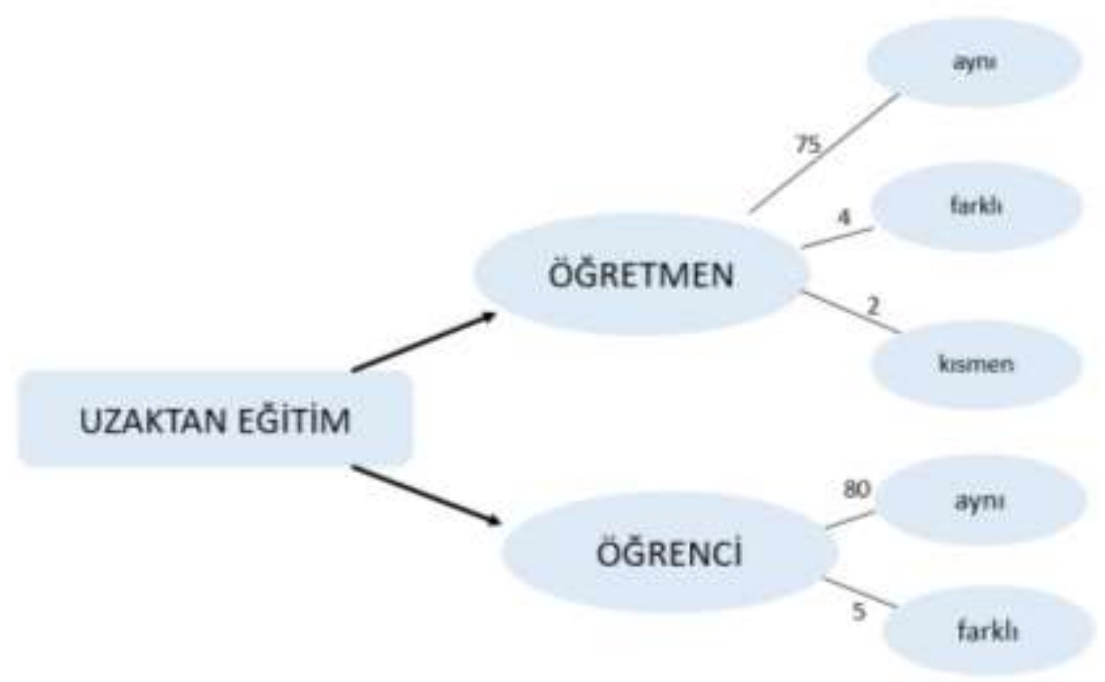

Şekil 2. Uzaktan eğitimde öğretmen ve öğrenci rollerine yönelik şematik gösterim

Öğrenciler tarafından verilen ifadeler şema üzerinde gösterilmeye çalışılmıştır. Uzaktan eğitimde öğretmen ve öğrencinin rolüne yönelik ifadelerin yer aldığı șemada toplam 166 kodun, 8 kategoride atamaları yapılmış olup; tek yönlü oklar birincil, diğerleri ise ikincil bağlantıları ifade etmektedir.

Ö.9“...Evet aynı ama zorlayıcı yönleri var biz ögrrenciler açısından.

Çünkü Hocalarımız ile yüz yüze iletişim daha başarılı olmamızı

sağllyor. Bu süreçte ise Hocalarımız bizlerle her zaman olduğu

gibi ilgili ve alakall"

Ö.24“...Aynı sayılır örgün eğitimi de yüz yüze eğitim 
görüyoruz konu hakkında daha fazla soru sorma firsatımız oluyor"

Ö.39“...Hayır aynı değildir. Örgün eğitimde öğretmen ile öğrenci devamlı iletişim halindedir"

Ö.8“...Örgün eğitimde ögrretmenler ile yüz yüze bir soruyu sorabiliyor ve ögrrenebiliyoruz. Ancak uzaktan eğitim sisteminde ise bunun pek mümkün olduğunu düşünmüyorum”

Ö.11 “....Kesinlikle rolü aynı değildir. Çünkü uzaktan eğitimde bedensel olarak diyalog kurulamıyor. İletişim kurulamadiğı için de derse katılım dikkat sağlanamıyor" Ö.4“...neredeyse aynı, evet örgün eğitiminde de yüz yüze anlatıyor uzaktan öğretimde de fakat büyük bir çaba var, öğretmenler düşünülünce her türlü teknolojik açıdan daha çok yükleniliyor tüm öğrenciler bilgisayar üzerinden gönderim yapıyor ve hepsiyle iletiş̧imin kolay kurulamadiğııı düşünüyorum ve normalde olmayacak sorunlarla uğraşıyorlar o yüzden aynı değildir",

Ö.29“... Birebir eğitimin artısı illaki oluyor anlık sorunlara anlık çözümler üretebiliyoruz. Onun haricinde rolleri aynı geliyor.

Yine eğitimimizi almaya devam ediyoruz"

Ö.47 "anlatılmak istenilen ile anlaşılan farklı olabiliyor.

Görsellerle desteklenebilir olmasina rağmen yine de öğrenci

anladı̆̆ kadarıyla tasarımları yapıp gönderme aşamasında

bile sorunlar çıkabiliyor"

Ö.52“...Örgün eğitimde olduğu gibi uzaktan eğitimi de ciddiye almast, aksatmamast, dersi derste dinlemesi ve gereken şeyleri eksiksiz yerine getirmesidir"

Verilen cevaplara bakıldığında hem öğretmen hem de öğrenci için örgün eğitim gibi yüzyüze, ders saatleri içinde atölyeyi aktif kullanma, öğretmenin eleştirilerinden maksimum düzeyde faydalanma gibi imkânları olmamakla beraber, rollerin aynı olduğu görülmektedir. Unutulmamalıdır ki Grafik Tasarım Bölümü yetenek sınavıyla öğrenci kabul etmektedir. Dolayısıyla karşımızdaki öğrenci profili diğer disiplinlerde kayıtlı öğrenci profilinden farklıdır. Düzenlenen eğitim-öğretim ortamı "uzaktan” da olsa öğretmenin yaklaşımı, derse ilgi ve başarı artışında paralel seyir göstermiştir. Ayrıca öğretmenin derse hâkimiyetinin yanında etkli iletişim becerilerine de sahip olmas1 gerekmektdir.

Tablo 4. Öğretimin uzaktan eğitimle yapılabilmesine yönelik dağılım

\begin{tabular}{cccl}
\hline & Değişken & $\mathrm{f}$ & $\%$ \\
Uzaktan & yapılabilir & 22 & 25 \\
Eğitim & yapilamaz & 55 & 62,5 \\
& kısmen & 11 & 12,5 \\
\hline TOPLAM & & 88 & 100 \\
\hline
\end{tabular}


Tablo 4 incelendiğinde çalışma grubunun; \%25'inin (22) yapılabilir, \% 62,5'inin (55) yapılamaz, \%12,5'inin (11) kısmen cevabını verdiği görülmektedir. Yorumlara bakılınca teorik derslerin yapılmasında problem görünmezken, uygulamalı atölye derslerinde malzeme, teknik donanım gibi atölye ortamında bulunan malzemelere sahip olmamak dersin uygulamasını yapmayı zorlaştıracaktır.

Tablo 5. Derslerin senkron/asenkron izlenmesine yönelik dağılım

\begin{tabular}{lccc}
\hline & Değişken & $\mathrm{f}$ & $\%$ \\
Senkron/ & kolaydır & 30 & 34,09 \\
asenkron & kolay değildir & 58 & 65,9 \\
izlemek & & 88 & 100 \\
\hline TOPLAM & &
\end{tabular}

Tablo 5 incelendiğinde çalışma grubunun derslerin senkron/asenkron izlenmesinin; \%34,9’unun (30) kolay, \% 65,9’unun (58) kolay olmadığı cevabını verdiği görülmektedir.

Tablo 6. Dersleri kamera karşısında yapmaya yönelik dağı̆lım

\begin{tabular}{lccc}
\hline & Değişken & $\mathrm{f}$ & $\%$ \\
Senkron/ & evet & 40 & 45,5 \\
asenkron & hayır & 39 & 44,3 \\
izlemek & kismen & 9 & 10,2 \\
\hline TOPLAM & & 88 & 100 \\
\hline
\end{tabular}

Tablo 6 incelendiğinde çalışma grubunun dersleri kamera karşısında yapmaya yönelik dağılımda; \% 45,5'inin (40) evet, \% 44,3'ünün (39) hayır ve \%10,2'sinin (9) kısmen cevabını verdiği görülmektedir.

Tablo 5 ve 6'nın bulgularına bakıldığında, genel olarak derslerin izlenmesinin kolay olmadığı sonucuna ulaşılmıştır. Buda öğrencinin bulunduğu ortam, internet sağlayıcısının hızı ve zamanı ergonomik kullanamama gibi sebeplerden kaynaklanmaktadır. Dersler sırasında oluşan olumsuzluklar öğrencilerin kişisel problemlerinden kaynaklanmaktadır. Ayrıca senkron ya da asenkron izlemenin küçük bir farkla dersleri senkron izlemenin olumlu yönde verileri olduğu görülmüştür. Bu sorunun cevabında da tamamen öğrencinin sahip olduğu teknik donanımla ilgilidir.

Araştırmada alt amaçları desteklemek için sorgulanan bir diğer soru UZEM sistemi veya mail, whatsapp... gibi araçlarla ödev gönderirken yaşanan sıkıntıların belirlenmesidir. Bulgular aşağıdaki başlıkta yorumlanmıştır.

Tablo 7. Ödev gönderirken yaşanan sorunlara yönelik kodlama

\begin{tabular}{lc}
\hline \multicolumn{1}{c}{ Kategoriler } & Kodlama \\
\hline Beğenilenler & 5 \\
\hline Hiçbir sorun yaşamadım & 7 \\
\hline Sistem güzel çalışıyor & 2 \\
\hline Henüz denemedim & \\
\hline Hep kullanabiliriz & 15 \\
\hline Beğenilmeyenler & 18 \\
\hline Dosya boyutu büyük olunca sorun yaşadım & 12 \\
\hline İnternetin yavaşlığı & 25 \\
\hline Ulaşı1p ulaşmama ikilemi & 8 \\
\hline Çok sorunlu & 6 \\
\hline Geç yükleniyor &
\end{tabular}


Çalışmada öğrencilerin ödev gönderme sürecinde yaşadıkları sıkıntıları anlatmaları istendiğinde Tablo 7'de görüldüğ̈̈ gibi kod ve kategoriler ortaya çıkmıştır. Yukarıdaki tabloda toplam 99 kodun, 12 kategoride atamaları yapılmıştır. Bağlantı üzerindeki rakamlar öğrencilerin yüklemelerini ifade etmektedir. Sayısal değeri bulunmayan yüklemeler rakamsal olarak "1" değerini taşımaktadır. Bir öğrenci bir veya daha fazla yükleme yapabileceği için uygulamaya katılan öğrenci sayısı ile yükleme yapan öğrenci sayısı birbirinden farklı olabilir. Tablo 7 incelenirken bu durum göz önünde bulundurulmalıdır.

$\mathrm{Bu}$ sürecin örgün eğitimden farklı olduğu bilinmektedir ve bu bilinçle tüm öğrenciler üzerine düşen görevleri yerine getirmiş kendi otokontrol mekanizmalarını kullanmayı öğrenmişlerdir. Ancak bilgisayar programları kullanılarak yapılan tasarımların kaydetme ve iletme seçeneklerinde boyut anlamında ayarlayamama gibi bir problemi aşamadıkları görülmüştür. Dolayısıyla internet donanımının yetersizliği, tasarımlarda boyut büyüklüğü ve büyüklüğe bağlı ödevlerin geç yüklenmesi neredeyse tüm öğrencilerin problemi olmuştur. Ayrıca ödevlerin mail ya da UZEM sistemine yüklenmesi gerekliliği olması halinde ödevlerin ulaşıp ulaşmadığı çalışmaya katılan öğrencilerin merakını çekmiş ve telaşlanmalarına neden olmuştur.

Tablo 8. Uzaktan eğitimde kullanılan donanımlara yönelik dağılım

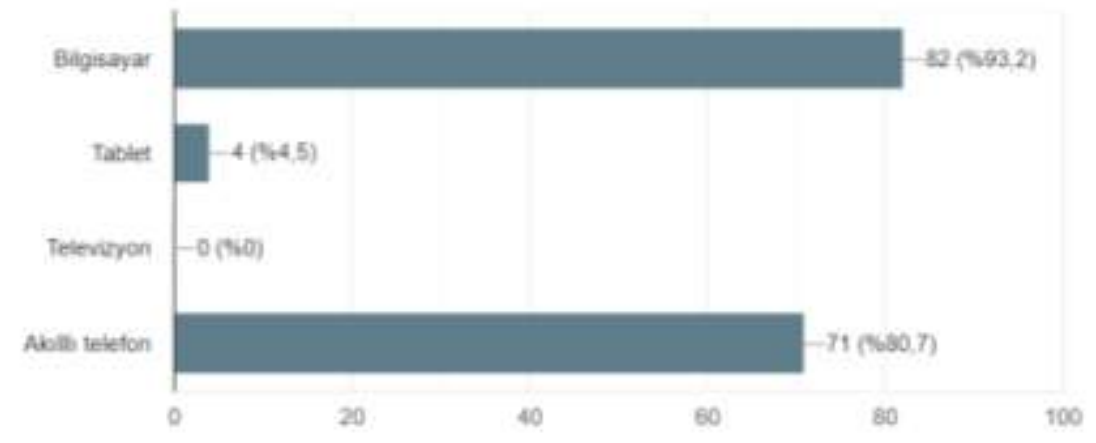

Tablo 8 incelendiğinde çalışma grubunun uzaktan eğitimde kullanılan donanımlara yönelik dağılımda; \%93,2'sinin (82) bilgisayar, \% 80,7'sinin (71) akı1lı telefon ve \%4,5'inin (4) tablet kullandığ 1 görülmektedir. Tabloya göre çoğunlukla bilgisayar ve akıllı telefon kullanımı ile uzaktan eğitim derslerini yürüttükleri görülmektedir.

Ayrıca iletişim teknolojisi kullanım sürelerine bakıldığında \%60,2'sinin (53) sürekli aktif, \%22,7'sinin (20) 4-6 saat arası aktif olduğu görülmüştür.

\section{Tartışma ve Sonuç}

$\mathrm{Bu}$ bölümde, araştırmadan elde edilen bulgulara dayanarak sonuçlar elde edilmiş ve tartışılmıştır. Ayrıca bu sonuçlarla ilgili önerilere yer verilmiştir.

Araştırma, COVID-19 pandemi sürecinde Kastamonu Üniversitesi Güzel Sanatlar ve Tasarım Fakültesi Grafik Tasarım Bölümü öğrencilerinin sürecin işleyiş̧i ile ilgili görüşlerini almak amacıyla yapılmıştır.

Araştırmanın 1. cevap aranan sorusuna göre uzaktan eğitimin tanımı yapılmıştır. Uzaktan eğitim, bir okulda her zaman fiziksel olarak bulunamayan öğrencilerin eğitimidir. Uzaktan eğitim, sınıftaki bir öğretmenle düzenli olarak yüz yüze iletişim kurmadan uzaktan öğrenmenin bir yoludur. Uzaktan eğitim tanım gereği kurumlar aracılığıyla gerçekleştirilir. Coğrafi ayrılma uzaktan öğrenmenin doğasında vardır, erişilebilirlik ve rahatlık, bu eğitim tarzının önemli avantajlarıdır. Uzaktan öğrenme bazen, sosyal medya kullanıcısı öğrencilerin profil oluşturması ve paylaşması etkinlikleriyle benzer düşünen öğrenciler arasında bağlantı sağlar ve izolasyon 
düşüncelerini azaltabilir. Araştırmada yer verilen öğrencilerin genel olarak uzaktan eğitim sisteminin ne anlama geldiği, içeriği hakkında bilgi sahibi oldukları görülmüştür.

Araştırmanın 2. ve 3. soruların cevabı için katılımcılar; uzaktan eğitim uygulamalarının teorik derslerde sanal sınıf ortamında örgün eğitim gibi işlendiğini ancak uygulamalı bölüm derslerinde atölye ortamında yapılması gereken derslerin çok verimli olmadığını belirtmişlerdir.

Uzaktan eğitim, öğrenen ve öğreten arasında uygun iletişim donanımları ile yapılan eğitici işlemsel mesafedir. Yapılan araştırmada elde edilen verilere göre, uzaktan eğitim uygulamalarının öğrenci ve öğretmen arasındaki iletişim, öğrenme süreci ve uzaktan erişim çabaları üzerinde doğrudan etkileri olduğu gözlenmiş̧ir.

Teknolojik gelişmelerin sunduğu birç̧ok araç ve programla, öğrenciler ve öğretmenler ile öğrenciler ve sınıf arkadaşları arasındaki bilgi alışverişi ve iletişim sayısı, uzaktan eğitimde örgün eğitimden daha fazla olduğu görülmüsstür. Pandemi sürecindeki kısitlamalar neticesinde, konuların ve uygulamaların bireysel anlamda anlaşılması çabası bu sonucu ortaya çıkarmış olabilir.

Uzaktan eğitim sistemlerinde kaydedilen gelişme, sürekli devinim halinde olup, teknolojik gelişmelerle paralellik arzetmektedir.

Uzaktan eğitim, ayrıca; bireylere şu anda mevcut olan en iyi üniversitelerin uzmanlık ve kaynaklarından yararlanma konusunda önemli bir firsat sunmaktadır. Öğrenciler, içeriğin sürekli iyileştirilmesi için işbirliği yapma, paylaşma, soru sorma, çıkarım yapma ve yeni yöntem ve teknikler önerme yeteneğine sahiptir. Bu anlamda yapılacak araştırmalarla bireysel farklılıklara göre, uygulamalar geliştirilebilir.

Uzaktan eğitim günümüz teknolojileri ile hemen her ortama uyarlanabilir bir eğitim sistemidir. $\mathrm{Bu}$ açıdan internet erişimli akıllı telefon, tablet vb. gibi mobil cihazlarla sisteme akredite olan bireylerin imkân, yaklaşım ve çalışma hızına göre maksimum esneklik ve yetenek sağlar.

Uzaktan eğitim sağlayıcıları, evrensel bir bakış açısı, esnek bir yaklaşım ve yaşam boyu öğrenme koşulları temelinde; katılımcı ve eğitici arasındaki etkileşim olanak ve imkânlarını artırmak için çeşitli stratejiler, teknikler, prosedürler ve uygulamaya yönelik çalışmalar geliştirebilirler. Etkileşimin artması bakımından yapılabilecekler şu şekilde sıralanabilir:

Uygulamalı alanlarda yüz yüze eğitimi destekleyici olacak şekilde uzakta eğitim etkinlikleri de ayrıca ve eşzamanlı olarak planlanabilir. İnternet tabanlı, telekonferans uygulamalarının (internet hız ve kalitesi dâhil olmak üzere) ve bilgi-iletişim teknolojilerinin her ortamda, ulaşılabilirliği ve artan kullanımı sağlanmalıdır. Şu an yaşadığımız covit-19 pandemi süreci gibi bundan sonra yaşanabilecek benzer durumlara yönelik eğitim öğretim planlamaları yapılmalıdır. Bu anlamda olası senaryolar üretilmeli ve erken uyarı ve tedbir anlamında eğitim-öğretimin aksamamasına yönelik yaklaşımlar güncellenmeli, ders aktivite ve programları hazırlanmalı, planlamalar geliştirilmelidir. Eğitim devamlılığı açısından tasarlanan uzaktan eğitim sistemi her fakülte ve bölüm için kendi iç dinamikleri göz önünde bulundurularak hazırlanmalıdır. Daha çok teorik derslerin işlenmesinde uygun görünen uzaktan eğitim sistemi uygulamalı dersler bakımından katılımcı ve paydaş görüşleri ile ayrıca değerlendirilebilir.

\section{Kaynakça}

Arslan, V. (2019). Web tabanlı uzaktan eğitim deneyimi ve verimliliği analizi: İstanbul Üniversitesi Örneği. [Yayımlanmamış yüksek lisans tezi]. İstanbul Üniversitesi Fen Bilimleri Enstitüsü. https://doi.org/10.5152/imj.2018.76158

Barış, M. F. \& Mevsim, E. (2014). Türkiye'de uzaktan eğitim merkezi kuruluşu ve organizasyonu: Namık Kemal Üniversitesi örneği. Eğitim ve Öğretim Araştırmaları Dergisi Journal of 
Research in Education and Teaching 3(3), Makale no: 27 ISSN: 2146-9199. https://doi.org/10.14527/331

Duran, N., Önal, A. \& Kurtuluş, C. (2006). E-Öğrenme ve kurumsal eğitimde yeni yaklaşım öğrenim yönetim sistemleri, Akademik Bilişim, http://docplayer.biz.tr/1451448-E-ogrenme-vekurumsal-egitimde-yeni-yaklasimogrenim-yonetim-sistemleri.html https://doi.org/10.31123/akil.437327

Genç, M. F., Gümrükçüoğlu, S. (2020). Koronavirüs (Covid-19) sürecinde ilâhiyat fakültesi öğrencilerinin uzaktan eğitime bakışları. Turkish Studies, 15(4), 403-422. https://dx.doi.org/10.7827/TurkishStudies.43798

Guba, E. G. \& Lincoln, Y. S. (1994). Competing paradigms in qualitative research. Handbook of Qualitative Research, 2 (105).

İşman, A. (2011). Uzaktan eğitim. Pegem Akademi.

Kaya, Z. (2002). Bazı uzaktan eğitim uygulamaları, uzaktan eğitim. Pegem A Yayınları. ISBN $975-$ 6802-82-0.

https://doi.org/10.21565/ozelegitimdergisi.554714

Kaynak, İ. (2020). Koronavirüs (Covid-19) algısının online alışverişe etkisi. Turkish Studies, 15(4), 633-645. https://dx.doi.org/10.7827/TurkishStudies.44391

Kırali, F. \& N., Alc1, B.(2016) Üniversite öğrencilerinin uzaktan eğitim algısına ilişkin görüşleri. Ístanbul Aydin Üniversitesi Dergisi. 30 (55-83).

Klenke, K. (2016). Qualitative research in the study of leadership. Emerald Group Publishing Limited.

Özmen, A. \& Gediz, İ. O. (2002). Uzaktan eğitim ve Dumlupınar Üniversitesi modeli. Açık ve Uzaktan Eğitim Sempozyumu. https://doi.org/10.14527/9786052412411.01

Tarlakazan, E. (2011). Görsel sanatlar dersinin işbirlikli öğretme yöntemi etkinlikleri ile gerçekleştirilmesine ilişkin öğrenci görüşlerinin değerlendirilmesi. E-Journal of New World Sciences Academy (NWSA). 6 (1).

Yavuz, R. (2016). Eğitim Fakültesi 1. sınıf öğrencilerinin uzaktan eğitime ve ingilizce dersine ilişkin tutumları arasındaki ilişki. [Yayımlanmamış yüksek lisans tezi]. Abant İzzet Baysal Üniversitesi Eğitim Bilimleri Enstitüsü Eğitim Bilimleri Anabilim Dalı Eğitim Programları ve Öğretimi Bilim Dalı. https://doi.org/10.17679/inuefd.399079

Yıldırım, A. \& Şimşek, H. (2008). Sosyal bilimlerde nitel araştırma yöntemleri. Seçkin Yayıncılık. 